\section{Cómo presentar los resultados del metaanálisis de estudios por observación}

La plétora de información en la literatura científica y la importancia de tomar decisiones oportunas y acertadas en el ámbito clínico imponen la necesidad de sintetizar los resultados de las investigaciones. El metaanálisis, método que sirve para identificar, evaluar, resumir y examinar en su conjunto los resultados de estudios sobre un mismo tema a fin de llegar a conclusiones generales, se aplica con frecuencia a ensayos clínicos aleatorizados, que proporcionan las pruebas más fidedignas de la eficacia de una intervención.

Hay situaciones, sin embargo, en las que no es factible realizar ensayos clínicos aleatorizados y se torna necesario recurrir a estudios transversales, series de casos, estudios de casos y testigos o estudios de cohorte. En estos diseños por observación, los pacientes no son asignados a un grupo $\mathrm{u}$ otro aleatoriamente y las conclusiones dependen de la presencia o ausencia de una asociación entre los cambios observados en una exposición o intervención y en la principal variable de interés. Los estudios de observación son especialmente útiles para determinar la eficacia de una intervención en la comunidad, y no en las condiciones artificiales en que se efectúan los ensayos clínicos. Por todos estos motivos, se necesita tener muy presentes las ventajas y limitaciones de los metaanálisis de estudios por observación, los cuales, pese a las muchas dificultades que entrañan, pueden ayudar a precisar y cuantificar los factores que explican la variabilidad de los resultados de estudios.

En las últimos cuatro decenios, el número de metaanálisis publicados que se basan en estudios por observación ha aumentado notablemente (678 en 1955-1992, 525 en 1992-1995). Aunque se han recomendado pautas para llevar a cabo los metaanálisis de estudios por observación, estas casi siempre han sido elaboradas desde el punto de vista del autor, y no del revisor, del editor o del lector.

En abril de 1997 se reunieron en Atlanta, Georgia, 27 expertos -médicos, estadísticos, investigadores, epidemiólogos, sociólogos y editores científicos-, a fin de examinar la presentación de los metaanálisis de estudios por observación y hacer recomendaciones pertinentes que fueran de utilidad para los autores, revisores, editores y lectores.
Llevaron a cabo una revisión sistematizada de la literatura sobre el tema en MEDLINE, el Educational Resources Information Center, PsycLIT y el Current Index to Statistics e identificaron 32 artículos que sirvieron para elegir los temas debatidos en el taller: sesgos, búsqueda bibliográfica, elaboración de resúmenes, heterogeneidad, clasificación de estudios y métodos estadísticos. Tras amplias deliberaciones en sesiones plenarias y talleres, se confeccionó una lista de los aspectos que merecían mayor atención, que fueron los siguientes: la manera de presentar los antecedentes, la estrategia de búsqueda, los métodos, los resultados, la discusión y las conclusiones. Los puntos detallados a continuación se consideraron componentes esenciales de la lista.

Antecedentes: definición del problema examinado; hipótesis fundamental; descripción de los resultados de interés; tipo de exposición o intervención; diseño metodológico; descripción de la población estudiada.

Búsqueda bibliográfica: credenciales de los investigadores; bases de datos consultadas; estrategia de búsqueda; términos empleados para hacer la búsqueda; uso de alguna función de búsqueda especial; software utilizado; búsqueda manual y contacto con los autores; uso de materiales en idiomas distintos del inglés; uso de materiales inéditos, y criterios de exclusión que fueron aplicados.

Métodos: idoneidad de la síntesis cuantitativa de los datos; grado de minuciosidad y objetividad en la codificación de los datos; evaluación de los factores de confusión; calidad y heterogeneidad de los estudios; aplicación de métodos estadísticos y presentación de sus resultados. Según pruebas empíricas, estos aspectos a menudo se describen de forma superficial o incompleta. Aunque la asignación de puntos para cuantificar la calidad de los estudios puede plantear problemas de validez, se ha demostrado que algunos aspectos de la calidad se asocian con los resultados obtenidos - un ejemplo es el enmascaramiento adecuado de los sujetos en estudios aleatorizados-, de manera que tienen mayor importancia ciertos componentes del diseño que la simple agregación de las mediciones de calidad. Aunque es posible aplicar criterios de exclusión para controlar la heterogeneidad de los estudios, se recomienda aplicar criterios de inclusión muy amplios y realizar análisis estratificados o de regresión posteriormente, teniendo en cuenta as- 
pectos específicos del diseño, para correlacionar este último con los resultados obtenidos.

Resultados: Se recomienda resumir en gráficos los resultados aislados o combinados de los estudios incluidos en el metaanálisis y presentar un cuadro con datos descriptivos sobre cada estudio, los resultados de las pruebas de sensibilidad y cualquier análisis de subgrupos, y alguna indicación de la fiabilidad estadística de los resultados.

Discusión: La discusión debe abarcar los sesgos implícitos en el diseño y los factores de confusión que podrían haber influido en los resultados. Puede haber sesgos en los estudios originales, o como resultado de la selección de los estudios incluidos en el metaanálisis. Los sesgos de publicación, consecuencia de la selección de estudios basada en la magnitud y la índole de sus resultados, son especialmente comunes en los metaanálisis de los estudios por observación.

Conclusiones: Debido a los sesgos que a menudo afectan a los estudios por observación, las conclusiones de los metaanálisis deben incluir comentarios sobre las distintas explicaciones que podrían tener los resultados observados. También es necesario mencionar las áreas donde hacen falta más investigaciones y las entidades que han auspiciado los estudios comprendidos en el metaanálisis, ya que la procedencia de los fondos ha sido una fuente comprobada de heterogeneidad.

Esta lista será sometida a futuras revisiones. (Stroup DF, Berlin JA, Mortin SC, Olkin I, Williamson D, Rennie D, et al. Meta-analysis of observational studies in epidemiology. JAMA 2000;283(15): 2008-2012.)

\section{Debate sobre cuándo suspender la vacunación contra la poliomielitis}

Ahora que la campaña para la erradicación mundial de la poliomielitis ha llegado a su fase final, los científicos debaten cuándo y cómo debe suspenderse la vacunación contra la enfermedad una vez que esta haya sido erradicada. Los aspectos principales del debate se presentan en el número de marzo de 2000 del Bulletin of the World Health Organization.

Desde 1988, cuando la Asamblea Mundial de la Salud adoptó la resolución de erradicar la poliomielitis para el año 2000, el poliovirus salvaje ha sido eliminado de tres de los cinco continentes. El número de casos en el mundo se ha reducido en más de 95\%, hasta llegar a la cifra inusitadamente baja de 20000 casos en 1999, casi todos en Bangladesh, Etiopía, India, Nigeria y Paquistán. Ha habido grandes adelantos en estos países, así como en muchos otros donde la batalla contra la enfermedad ha sido muy difícil.

Muchos de los países donde la guerra y los conflictos internos han contribuido a la desintegración de los sistemas de salud han encontrado la manera de vacunar a los niños contra la poliomielitis. En 1999, los trabajadores de salud en la República Democrática del Congo vacunaron a más de ocho millones de niños durante una tregua mediada por las Naciones Unidas. Angola, Afganistán, Somalia y el sur del Sudán también lograron vacunar a millones de niños durante las campañas nacionales de inmunización.

Estos adelantos fomentan la esperanza de que la poliomielitis haya sido erradicada cuando llegue la fecha oficial establecida para la "certificación" en 2005. No obstante, la enfermedad seguirá planteando algunos problemas aun después de esa fecha, entre ellos su posible reaparición al cabo de unos años. Esta posibilidad se presenta en toda iniciativa de erradicación.

En el caso de la poliomielitis, es bien sabido que los poliovirus que contiene la vacuna pueden transmitirse entre individuos vacunados y de una persona vacunada a sus contactos. Algunos investigadores se preocupan por la posibilidad de que estos virus sigan alojados en el organismo de algunas personas después de suspendida la vacunación. No obstante, los estudios que se han llevado a cabo en diversos países no han dado indicios de que el virus siga circulando después del cese de la inmunización. Pese a estos estudios, algunos expertos han manifestado su inquietud al respecto porque, con el paso del tiempo, cada nueva generación que no ha tenido exposición al poliovirus se hará más susceptible a él, pudiendo surgir incluso la amenaza futura de una transmisión de proporciones epidémicas. Lo más importante es proteger a la población. De ahí que saber cómo y cuándo suspender la vacunación es una decisión que reviste una importancia decisiva en el contexto de la iniciativa de erradicación.

Después de la erradicación, la única fuente de poliovirus salvajes serán los laboratorios. La OMS ha ideado un plan de acción a escala mundial y un itinerario para la manipulación y el almacenamiento sin riesgos de estos y otros materiales peligrosos. Los laboratorios deberán adoptar rigurosas medidas de seguridad y destruir sus reservorios de virus o trasladarlos a depósitos especiales designados por la OMS. Aunque ello parezca sencillo, no todos los laboratorios llevan un inventario minucioso de sus reservorios víricos, de manera que los países deberán implantar medidas para ubicar todos y cada uno de los reservorios existentes.

En resumen, a la hora de determinar cómo y cuándo suspender la vacunación antipoliomielítica 
una vez que se haya erradicado la enfermedad, habrá que tener en cuenta los conocimientos científicos más recientes, los resultados de análisis de costos y beneficios, la factibilidad de responder a distintas eventualidades, la disponibilidad de vacunas contra la poliomielitis y el respaldo de los distintos comités decisorios en el mundo. (World Health Organization. Scientists debate when and how to stop polio vaccination after the disease is eradicated. Comunicado de prensa $\mathrm{WHO} / 24$, abril de 2000.)

\section{¿Podrá encontrarse una vacuna contra la enfermedad de Alzheimer? Algunos opinan que sí.}

La inoculación de un individuo con un virus o una bacteria atenuada para estimular la producción de anticuerpos es un concepto sencillo que se ha llevado a la práctica una y otra vez con resultados extraordinarios en la lucha contra muchas enfermedades, desde la viruela hasta la poliomielitis y el sarampión. Ahora algunos científicos abrigan la esperanza de poder aplicarlo en la batalla contra la enfermedad de Alzheimer.

En 1999, un grupo de investigadores de la compañía farmacéutica Elan ha explorado esta posibilidad mediante el desarrollo de un modelo a base de ratones transgénicos en cuyo ADN insertaron una variante mutante del gen de la proteína precursora del amiloide, que es responsable de una forma genética de la enfermedad de Alzheimer. Los ratones fabricaron la proteína mutante y con el tiempo sufrieron la aparición de placas de amiloide. Los investigadores pudieron usar este modelo para investigar la eficacia de distintos tratamientos contra la formación de placas. El paso siguiente fue la creación de una vacuna a base de amiloide beta y una sustancia que estimula el sistema inmunitario. En un primer experimento, le administraron a un grupo de ratones transgénicos inyecciones mensuales de la vacuna, entre los 6 y 11 meses de edad. A un segundo grupo de estos ratones, que sirvió de grupo testigo, no le administraron ninguna vacuna. A la edad de 13 meses, los ratones del grupo testigo tenían placas en 2 a $6 \%$ del cerebro, mientras que los ratones vacunados estaban prácticamente libres de placas.

En un segundo experimento, los investigadores empezaron a administrar las inyecciones a los 11 meses de edad, cuando ya habían aparecido algunas placas. En un período de 7 meses, los ratones transgénicos que sirvieron de testigos mostraron un aumento de $1700 \%$ en la cantidad de placas cerebrales, mientras que los ratones que fueron vacunados mostraron un descenso de $99 \%$ en comparación con los ratones testigos de 18 meses de edad. En algunos ratones, el tratamiento parece haber causado la desaparición de algunas de las placas que ya estaban presentes y la reducción de algunos de los otros daños que suelen acompañarlas, como la inflamación y la alteración de los procesos celulares.

Este estudio es de carácter preliminar y falta mucho para poderlo repetir. Es necesario averiguar, por ejemplo, si los ratones vacunados se conservan en buena salud y con la memoria intacta después de la vacunación. Por otra parte, los ratones transgénicos no reproducen con exactitud los trastornos observados en seres humanos - no presentan nudillos neurofibrilares ni pierden tantas neuronas-, lo cual plantea la necesidad de llevar a cabo estudios para determinar si los seres humanos responden de manera distinta a la vacuna. También es importante tener en cuenta que el depósito de amiloide es un fenómeno que se presenta invariablemente en los seres humanos con enfermedad de Alzheimer, pero solamente una fracción de los casos de la enfermedad que se presentan en edad temprana se deben a la presencia de la variante mutante del gen de la proteína precursora del amiloide, lo cual implica que la vacuna podría ser beneficiosa en algunos casos solamente. Puede que "cure" el depósito de amiloide, pero que no impida la progresión de la demencia.

Existen algunas dificultades de carácter técnico. Falta verificar si es factible elaborar una vacuna que estimule la formación de anticuerpos contra las proteínas del propio organismo. Habrá que determinar la inocuidad y eficacia de la vacuna antes de contemplar la realización de ensayos en seres humanos.

Muy a pesar de estas limitaciones, el estudio aquí descrito representa un adelanto científico y conceptual de enorme importancia y podría representar un gran paso hacia el desarrollo de un tratamiento eficaz contra la enfermedad de Alzheimer. El estudio ha sido el resultado de una labor efectuada a lo largo de los últimos 20 años, con el respaldo del gobierno federal de los Estados Unidos de América y, en época más reciente, de los laboratorios farmacéuticos. Si la técnica que se ha explorado en ella da los resultados esperados, será factible curar una enfermedad que, según se estima, podría llegar a paralizar el sistema de salud en el próximo siglo. Y aun si esta técnica no diera resultados, puede ser la base para el descubrimiento de otros métodos inmunológicos para impedir el depósito de amiloide en la enfermedad de Alzheimer y otras enfermedades neurológicas. (National Institute on Aging. Immunizing against AD? A tantalizing possibility suggested by recent research. Progress reports 
on Alzheimer's disease. Bethesda, Maryland: NIA; 1999. p. 22. [NIH Publication 99-4664].)

\section{La carga de VIH en la sangre y el riesgo de transmisión por contacto heterosexual}

Mientras más bajas son las concentraciones de $\mathrm{VIH}$ en la sangre, resulta menos probable que una persona infectada transmita el virus a sus parejas heterosexuales, según un estudio efectuado en Uganda y auspiciado por los Institutos Nacionales de Salud (NIH) de los Estados Unidos de América. Un grupo de investigadores de varios países ha publicado los resultados de la encuesta más extensa que se haya efectuado hasta la fecha para determinar si existe una conexión entre la carga vírica en la sangre de un individuo infectado y otros factores que constituyen un riesgo para la transmisión de VIH entre personas heterosexuales. Los resultados parecen indicar que la carga vírica es el factor de mayor valor predictivo a la hora de determinar el riesgo de transmisión entre hombres y mujeres, independientemente del sexo del individuo transmisor.

La encuesta, que duró dos años y medio, fue aplicada a más de 400 parejas heterosexuales en las cuales solamente una de las dos personas era seropositiva a VIH. Se encontró que mientras más grande era la carga vírica del individuo, más altas eran las posibilidades de que transmitiera el virus a su pareja. En cambio, nadie con menos de 1500 copias de VIH por mililitro $(\mathrm{mL})$ de sangre transmitió el virus a su pareja sexual.

Los resultados confirman que es beneficioso reducir las concentraciones sanguíneas de VIH y que, aun en casos en que la infección no puede erradicarse del organismo, los medicamentos y las vacunas antirretrovíricas pueden ayudar a reducir la transmisión heterosexual de $\mathrm{VIH}$, que representa la principal vía de transmisión del sida en países del África y en muchas partes del mundo.

Hasta ahora el tratamiento con antirretrovíricos se ha considerado beneficioso para la persona infectada por VIH. No obstante, los resultados de este estudio indican que toda medida encaminada a reducir la carga vírica en un individuo determinado puede contribuir a controlar la epidemia de sida. Es especialmente importante encontrar métodos baratos y factibles de reducir la carga vírica en poblaciones de escasos recursos. Los investigadores también prestaron atención a otros factores de riesgo para la transmisión de VIH. En general, no detectaron ninguna diferencia estadística en la tasa de transmisión de hombre a mujer o de mujer a hombre, pero sí encontraron una asociación significativa entre la cir- cuncisión en el hombre y una menor transmisión de VIH. También observaron una mayor tasa de seroconversión en las parejas jóvenes (de 15 a 19 años de edad).

El proyecto realizado en Uganda ha sido el más extenso en haberse efectuado sobre la transmisión de VIH en el África, región del mundo que ha sido la más azotada por la epidemia de sida. El estudio también se distingue por su rigor científico y porque señala el camino hacia el desarrollo de nuevas intervenciones para prevenir la transmisión de VIH. (National Institute of Allergy and Infectious Diseases, National Institutes of Health. Low blood levels of HIV reduce risk of heterosexual transmission. Comunicado de prensa, 29 de marzo de 2000.)

\section{Los programas de desarrollo multisectoriales y su impacto en la salud}

Las instituciones públicas y privadas que participan en actividades de desarrollo social en el ámbito internacional se han mostrado interesadas en conocer los efectos que tienen sus programas, los cuales han sido objeto de muy pocos estudios. En la provincia de Inquisivi, Bolivia, lejos de La Paz, un grupo de investigadores ha puesto a prueba la hipótesis de que los programas de desarrollo multisectoriales tienen un mayor impacto en la salud que los programas de salud propiamente dichos. Desde 1986, Save the Children/US ha establecido en Inquisivi programas locales de desarrollo social con la participación de la comunidad. Primero se crearon programas de supervivencia infantil. Más tarde se empezó a movilizar a la comunidad en torno a actividades de salud reproductiva, y en 1992 y 1993, respectivamente, se iniciaron programas para alfabetizar a la población femenina y se organizaron los primeros programas de crédito monetario para mujeres.

A fin de poner su hipótesis a prueba, los investigadores compararon cuatro grupos de domicilios: 1) los que participaban en programas de salud auspiciados por Save the Children $(n=792) ; 2)$ los que tenían acceso a programas de salud y de crédito empresarial, o a programas de salud y de alfabetización $(n=360) ; 3)$ los que participaban en los tres programas, es decir, los de salud, alfabetización y crédito $(n=614) ; \mathrm{y} 4)$ los que estaban situados en comunidades cercanas sin acceso a programas auspiciados por Save the Children $(n=786)$. Los datos se obtuvieron de una muestra estratificada de 499 domicilios del territorio andino. Los resultados indican que no hay una asociación entre la participación en uno o más de los programas auspiciados 
por Save the Children y las medidas aplicadas por los padres para prevenir y tratar los episodios de diarrea. Por añadidura, la prevalencia de punto de la diarrea fue similar en los cuatro grupos. No obstante, los niños cuyos padres participaban en programas de salud, crédito y alfabetización tenían un riesgo de desnutrición mucho menor que los niños de co- munidades vecinas, aun después de hacer ajustes por el efecto de la clase social, las fuentes de agua de consumo, y la disponibilidad de servicios de salud en los resultados. (Gonzales F, Dearden K, Jimenez W. Do multi-sectoral development programmes affect health? A Bolivian case study. 1999;14(4):400-408.)

\section{$49^{a}$ Reunión Anual de la American Society of Tropical Medicine and Hygiene}

Fechas: 29 de octubre al 2 de noviembre de 2000

Lugar: Houston, Texas, Estados Unidos de América

Tema: Medicina tropical

La American Society of Tropical Medicine and Hygiene, entidad cuya misión es promover la prevención y el control de las enfermedades tropicales por medio de actividades educativas y de investigación, está integrada por alrededor de 3000 médicos, investigadores, científicos, estudiantes, profesores y funcionarios públicos. Estos miembros se dedican en su mayor parte a investigar los aspectos clínicos, epidemiológicos, bioquímicos, inmunológicos y moleculares de las enfermedades parasitarias, víricas y bacterianas propias de las zonas tropicales. Como metas específicas, la sociedad busca promover, en el campo de la salud internacional, la adopción de políticas basadas en los resultados de investigaciones; fomentar la colaboración entre países en materia de medicina tropical; reconocer los aportes de expertos destacados; despertar el interés de los profesionales en la medicina tropical, y estimular todo tipo de actividades de investigación. Este año la sociedad se complace en convocar a todo profesional interesado en estos temas a su 49ª reunión, en la que también se darán a conocer los últimos adelantos técnicos y farmacéuticos en el campo de la medicina tropical.

\section{Información: \\ ASTMH \\ P.O. Box 71482}

Chicago, Illinois 60694-1482

Estados Unidos de América

Teléfono: 847 480-9592

Fax: 847 480-9282

Correo electrónico: astmh@astmh.org 